\title{
Prevalence, Severity and Associated Factors of Dental Caries in 3-6 Year Old Children - A Cross Sectional Study
}

\author{
Maj Saravanan $\mathrm{SP}^{1, *}$, S Lokesh ${ }^{2}$, Tejaswin Polepalle ${ }^{3}$, Akhilesh Shewale ${ }^{4}$ \\ ${ }^{1}$ Periodontology, Armed Forces Medical College, Pune, Maharashtra, India \\ ${ }^{2}$ Paediatric Dentistry, Rajah Muthaiah Dental College \& Hospital, Chidambaram, Tamilnadu, India \\ ${ }^{3}$ Department of Periodontology, Sibar Dental College \& Hospital, Guntur, Andhra Pradesh, India \\ ${ }^{4}$ Periodontology, SDKS Dental College \& Hospital, Nagpur, Maharashtra, India \\ *Corresponding author: drsaravanan.sp@gmail.com
}

Received October 05, 2014; Revised October 16, 2014; Accepted October 28, 2014

\begin{abstract}
In the overall scheme of disease prevention, oral health is often overlooked. Oral health plays an important role in an individual's overall health. More than 90 percent of all systemic diseases have oral manifestations. Many diseases can be diagnosed in their early stages through an oral examination. Oral diseases and conditions may have a significant impact on general health; some poor general health conditions also may affect oral health status. The oral cavity is a portal of entry as well as the site of disease for microbial infections that affect general health status. Oral diseases affecting children include dental caries, early childhood caries (baby bottle tooth decay), periodontal diseases, other soft tissue diseases, congenital malformations and oral and facial injuries incurred through sports activities and child abuse. Although these may not be life threatening, yet they cause lot of morbidity, psychological stress and their treatment is expensive. Most oral diseases and injuries can be prevented by the proper and timely use of scientifically based and widely accepted preventive and educational regimens and interventions. Overall, dental and oral health care in India is not in optimal condition. There is, therefore, an urgent need to prevent the rising dental diseases in India.
\end{abstract}

Keywords: early childhood caries, caries prevalence, caries risk factors

Cite This Article: Maj Saravanan SP, S Lokesh, Tejaswin Polepalle, and Akhilesh Shewale, "Prevalence, Severity and Associated Factors of Dental Caries in 3-6 Year Old Children - A Cross Sectional Study." International Journal of Dental Sciences and Research, vol. 2, no. 6A (2014): 5-11. doi: 10.12691/ijdsr-2-6A-2.

\section{Introduction}

Oral health means more than just an attractive smile. Poor oral health and untreated oral diseases and conditions can have a significant impact on quality of life. And in many cases, the condition of the mouth mirrors the condition of the body as a whole. Oral health care is an important, but often neglected, component of total health care. The mouth reflects general health and well-being. Oral health is an essential and integral component of health throughout life. Oral diseases are progressive and cumulative, and become more common over time. A number of them start, or are caused, in childhood and ought to be preventable or more easily remediable if identified and treated early. Tooth decay (dental caries) is the most prevalent childhood disease. High caries prevalence still endures as one of the major oral health issues in children. Dental caries is 5 times more common than asthma and 7 times more common than hay fever in children. More than $40 \%$ of children have tooth decay by the time they reach kindergarten. Infants who are of low socioeconomic status, whose mothers have a low education level, and who consume sugary foods are 32 times more likely to have caries at the age of 3 years than children in whom those risk factors are not present. The deteriorating oral health conditions in the country have been revealed by various epidemiological studies. With increasing life expectancy (64.6 years) of the Indian population, oral health is bound to play a major role in improving the quality of life.

\section{Material \& Methods}

\subsection{Objectives}

1. To determine the prevalence and severity of dental caries in 3-6 year old children in cannanore.

2. To elucidate factors which are affecting the dental caries of 3-6 year old children

\subsection{Study Design \& Methods}

A cross-sectional study was done to measure the prevalence and severity of dental caries of 3-6 year old children and to study the association of dental caries with factors such as age, oral health practices, eating habits, 
socio-economic status and parent's educational level. The study site was all the schools of Cannanore. The study population consisted of children between age group of 36 years attending schools in Cannanore. The inclusion criteria included mental capacity to grasp and understand the questionnaire and children attending the school between the ages of 3-6 years (children with primary dentition). The exclusion criteria was children with poor communication skills who will not be able to respond correctly to the questions asked and children who do not cooperate for oral examination will be excluded from the study. As the prevalence of dental caries amongst children in our population is varied a prevalence of $50 \%$ was assumed to calculate the sample size using the formula $\mathrm{N}$ $=\left(\mathrm{Z}_{\alpha / 2} / \Delta\right)^{2} \mathrm{P}(1-\mathrm{P})$; Where $\mathrm{Z}_{\alpha / 2}$ is the level of significance, $\Delta$ is the Precision, $\mathrm{P}$ is the prevalence of dental caries. Assuming a prevalence of $50 \%$ of caries, with a precision of $5 \%$, and assuming a $30 \%$ non- response (or drop out) for a survey, the sample size was arrived at 500. The sampling technique followed was systematic random sampling. An instrument was developed for the purpose of the study, pre-tested and validated. Two questionnaires were prepared. One questionnaire containing the various risk factors to be measured and the dental caries indices were used on children to collect the relevant data. The various risk factors were obtained from the existing literature; the feasibility of measuring these risk factors in our population was assessed. A separate questionnaire was distributed to the parents to measure the socio economic status and to know the parents educational level. From the selected schools around thirty children from each class i.e. Prekg, LKG etc were sampled randomly using their attendance list and were included in the study. The questionnaire to record children's detail was interviewer administrated and all the sampled children underwent dental examination. Clinical examination was carried out using mouth mirror and explorer in a good natural light. Dental caries was diagnosed using visual and tactile method. The questionnaire containing parent's details was given to the children to take it to their houses, and was asked to be filled by their parents. The consent of the parents was taken by a separate consent form attached to the questionnaire.

\subsection{Data Management and Analysis}

The dmft and dmfs indices for each child was calculated and recorded in the questionnaire. All data including the different components of each index was entered in EXCEL. Chi-square test was done for comparison of categorical variables and $t$-test was done for comparison of continuous variables between two groups and f-test for more than two groups. Association between dental caries and associated factors was determined by calculating the Odd`s ratio. Logistic regression was performed to test the magnitude of association between dental caries and factors associated with it, and linear regression was done for continuous variables.

\section{Results}

\subsection{General Information}

Age, School and gender wise distribution of subjects

Totally 527 children were sampled for the study. Out of the 527 children 261 were boys and 266 were girls. 276 students from private and 251 students from government schools were included in the study. The number of study subjects from each age groups of 3, 4, 5, 6 were 122, 102, 168, 135 children respectively.

\section{Age and class wise distribution of subjects in different} sex

The proportion of boys and girls in each age group were almost equal $\left(\mathrm{X}^{2}=3.393, \mathrm{p}=.335\right)$. The number of boys and girls in each class were also almost uniform. $\left(\mathrm{X}^{2}\right.$ $=1.515, \mathrm{p}=.824)$. Distribution of subjects between private and government schools were also $\operatorname{similar}\left(\mathrm{X}^{2}=0.566, \mathrm{p}=\right.$ 0.253).

Comparison of oral hygiene practices and eating habits between private and government school children

Table 1. Oral hygiene practices in relation to schools

\begin{tabular}{|c|c|c|c|c|c|c|c|c|}
\hline \multirow{2}{*}{$\begin{array}{l}\text { Factors } \\
\text { Oral hygiene practices }\end{array}$} & \multicolumn{2}{|c|}{ Private } & \multicolumn{2}{|c|}{ Government } & \multicolumn{2}{|c|}{ Total } & \multirow{2}{*}{$X^{2}$} & \multirow{2}{*}{$p$ value } \\
\hline & No. & $\%$ & No. & $\%$ & No. & $\%$ & & \\
\hline $\begin{array}{l}\text { 1. How do you clean teeth } \\
\text { Finger } \\
\text { Brush }\end{array}$ & $\begin{array}{c}8 \\
268\end{array}$ & $\begin{array}{l}13.1 \\
57.5\end{array}$ & $\begin{array}{c}53 \\
198\end{array}$ & $\begin{array}{l}86.9 \\
42.5\end{array}$ & $\begin{array}{c}61 \\
466\end{array}$ & $\begin{array}{l}100 \\
100\end{array}$ & 42.62 & .0001 \\
\hline $\begin{array}{l}\text { 2. How often do you clean teeth } \\
\text { Once } \\
\text { Twice }\end{array}$ & $\begin{array}{c}224 \\
52\end{array}$ & $\begin{array}{l}49.9 \\
66.7\end{array}$ & $\begin{array}{c}225 \\
26\end{array}$ & $\begin{array}{l}50.1 \\
33.3\end{array}$ & $\begin{array}{c}449 \\
78\end{array}$ & $\begin{array}{l}100 \\
100\end{array}$ & 7.500 & .006 \\
\hline $\begin{array}{l}\text { 3. Materials used to clean teeth } \\
\text { Tooth paste } \\
\text { Tooth powder } \\
\text { Others }\end{array}$ & $\begin{array}{c}254 \\
22\end{array}$ & $\begin{array}{l}58.7 \\
23.7\end{array}$ & $\begin{array}{c}179 \\
71 \\
1 \\
\end{array}$ & $\begin{array}{l}41.3 \\
76.3 \\
100 \\
\end{array}$ & $\begin{array}{c}433 \\
93 \\
1 \\
\end{array}$ & $\begin{array}{l}100 \\
100\end{array}$ & 38.71 & .0001 \\
\hline $\begin{array}{l}\text { 4. How often do change brush } \\
1-3 \text { months } \\
\text { 4-6 months } \\
6+\text { months } \\
\text { When the brush is worn Others }\end{array}$ & $\begin{array}{c}9 \\
23 \\
89 \\
147 \\
8\end{array}$ & $\begin{array}{l}100 \\
85.2 \\
72.4 \\
47.9 \\
13.1\end{array}$ & $\begin{array}{c}4 \\
34 \\
160 \\
53\end{array}$ & $\begin{array}{l}14.8 \\
27.6 \\
52.1 \\
86.9\end{array}$ & $\begin{array}{c}9 \\
27 \\
123 \\
307 \\
61\end{array}$ & $\begin{array}{l}100 \\
100 \\
100 \\
100 \\
100\end{array}$ & 79.70 & .0001 \\
\hline $\begin{array}{l}\text { 5. How often do you rinse your mouth } \\
\text { Never } \\
\text { Sometimes } \\
\text { Always } \\
\text { Don't clean everyday }\end{array}$ & $\begin{array}{c}29 \\
139 \\
17 \\
91\end{array}$ & $\begin{array}{l}48.3 \\
53.1 \\
58.6 \\
51.7\end{array}$ & $\begin{array}{c}31 \\
123 \\
12 \\
85\end{array}$ & $\begin{array}{l}51.7 \\
46.9 \\
41.4 \\
48.3\end{array}$ & $\begin{array}{c}60 \\
262 \\
29 \\
176\end{array}$ & $\begin{array}{l}100 \\
100 \\
100 \\
100\end{array}$ & .927 & .819 \\
\hline
\end{tabular}


In private schools $57.5 \%$ of children use brush whereas only $42.5 \%$ of children use brush for cleaning their teeth in the government schools. There is high statistically significant difference between the mode of cleaning teeth between the private and corporation schools. $\left(\mathrm{X}^{2}=42.62\right.$, $\mathrm{p}=.001$ ). The numbers of children who brush twice are 52 in private schools whereas only 26 brush twice in government schools. The number of times of cleaning and the timings of their cleaning also differ significantly between the two groups. $\left(\mathrm{X}^{2}=7.5, \mathrm{p}=006\right)$.Comparing the materials used for brushing tooth paste was the material used mostly by the private school children for brushing (58.7\%) but only $41.3 \%$ of government school children used tooth paste for brushing. There was also statistical difference between the two schools in the timings of changing their brush $\left(X^{2}=79.7, p=001\right)$. The habit of rinsing the mouth was almost similar in both the schools

Table 2. Eating habits of children in relation to schools

\begin{tabular}{|c|c|c|c|c|c|c|c|c|}
\hline \multirow{2}{*}{$\begin{array}{l}\text { Factors } \\
\text { Eating Habits }\end{array}$} & \multicolumn{2}{|c|}{ Private } & \multicolumn{2}{|c|}{ Government } & \multicolumn{2}{|c|}{ Total } & \multirow[b]{2}{*}{$\mathrm{X}^{2}$} & \multirow[b]{2}{*}{ p value } \\
\hline & No. & $\%$ & No. & $\%$ & No. & $\%$ & & \\
\hline \multicolumn{9}{|l|}{ 1. Sugar bad for teeth } \\
\hline Yes & 174 & 57.4 & 129 & 42.6 & 303 & 100 & \multirow{3}{*}{7.49} & \multirow{3}{*}{.024} \\
\hline No & 19 & 48.7 & 20 & 51.3 & 39 & 100 & & \\
\hline Don't know & 83 & 44.9 & 102 & 55.1 & 185 & 100 & & \\
\hline \multicolumn{9}{|l|}{ 2. How many sweets taken } \\
\hline Not taken & 66 & 56.9 & 50 & 43.1 & 116 & 100 & \multirow{6}{*}{14.13} & \multirow{6}{*}{.015} \\
\hline One time & 118 & 52.4 & 107 & 47.6 & 225 & 100 & & \\
\hline Two time & 56 & 54.4 & 47 & 45.6 & 103 & 100 & & \\
\hline Four times & 25 & 59.5 & 17 & 40.5 & 42 & 100 & & \\
\hline Five times & 4 & 18.2 & 18 & 81.8 & 22 & 100 & & \\
\hline More than five times & 7 & 36.8 & 12 & 63.2 & 19 & 100 & & \\
\hline \multicolumn{9}{|l|}{ 3. When were sweets taken } \\
\hline During meals & 48 & 53.9 & 41 & 46.1 & 89 & 100 & \multirow[t]{3}{*}{.177} & \multirow[t]{3}{*}{.915} \\
\hline In between meals & 135 & 51.5 & 127 & 48.5 & 262 & 100 & & \\
\hline During and in between meals & 93 & 52.8 & 83 & 47.2 & 176 & 100 & & \\
\hline
\end{tabular}

In private school children $57.4 \%$ of them knew that sugar was bad for teeth whereas only $42.6 \%$ of the government school children had the knowledge of that sugar was bad for teeth. There was significant difference between the private and government schools on knowledge of whether sugar was bad for teeth. $\left(\mathrm{X}^{2}=7.5\right.$, $\mathrm{p}=$.024). There was also significant difference between the two schools in the number of sweets taken $\left(X^{2}=14.3\right.$, $\mathrm{p}=.015$ ), but the children of two groups were similar with respect to the timings of eating sweets.
Comparison of oral hygiene practices and eating habits between boys and girls

Oral hygiene practices in relation to gender

Overall 230 boys and 236 girls use brush for cleaning their teeth. This table reveals that there is no statistical difference in oral hygiene practices between males and females. This shows that the oral hygiene practices in males and females are almost similar. The materials used to clean the teeth, the timings of their cleaning their teeth their rinsing habits are similar in boys and girls.

Table 3. Eating habits in relation to gender

\begin{tabular}{|c|c|c|c|c|c|c|c|c|}
\hline Factors & \multicolumn{2}{|c|}{ Boys } & \multicolumn{2}{|c|}{ Girls } & \multicolumn{2}{|c|}{ Total } & \multirow[b]{2}{*}{$\mathrm{X}^{2}$} & \multirow{2}{*}{ p value } \\
\hline Eating Habits & No. & $\%$ & No. & $\%$ & No. & $\%$ & & \\
\hline \multicolumn{9}{|l|}{ 1. Sugar bad for teeth } \\
\hline Yes & 144 & 47.5 & 159 & 52.5 & 303 & 100 & \multirow{3}{*}{1.840} & \multirow{3}{*}{.399} \\
\hline No & 18 & 46.2 & 21 & 53.8 & 39 & 100 & & \\
\hline Don't know & 99 & 53.5 & 86 & 46.5 & 185 & 100 & & \\
\hline \multicolumn{9}{|l|}{ 2. How many sweets taken } \\
\hline Not taken & 60 & 51.7 & 56 & 48.3 & 116 & 100 & \multirow{6}{*}{2.175} & \multirow{6}{*}{.824} \\
\hline One time & 112 & 49.8 & 113 & 50.2 & 225 & 100 & & \\
\hline Two time & 52 & 50.5 & 51 & 49.5 & 1.3 & 100 & & \\
\hline Four times & 19 & 45.2 & 23 & 54.8 & 42 & 100 & & \\
\hline Five times & 8 & 36.4 & 14 & 63.6 & 22 & 100 & & \\
\hline More than five times & 10 & 52.6 & 9 & 47.4 & 19 & 100 & & \\
\hline \multicolumn{9}{|l|}{ 3. When were sweets taken } \\
\hline During meals & 43 & 48.3 & 46 & 51.7 & 89 & 100 & \multirow[t]{3}{*}{.160} & \multirow[t]{3}{*}{.923} \\
\hline In between meals & 132 & 50.4 & 130 & 49.6 & 262 & 100 & & \\
\hline During and in between meals & 86 & 48.9 & 90 & 51.1 & 176 & 100 & & \\
\hline
\end{tabular}

The knowledge in boys and girls regarding whether sugar was bad for teeth was $\operatorname{similar}\left(\mathrm{X}^{2}=1.84, \mathrm{p}=0.399\right)$. The number of sweets eaten and timings of eating them were also almost similar between them. The table reveals no statistically significant difference in eating habits between male and female children.

Prevalence and severity of dental caries 
Table 4. Dental caries prevalence in age group, classes and gender

\begin{tabular}{|l|c|c|c|c|c|c|}
\hline \multirow{2}{*}{ Factors } & \multicolumn{2}{|c|}{ DC prevalence } & \multicolumn{2}{|c|}{ Total } & \multirow{2}{*}{$\mathbf{X}^{\mathbf{2}}$} & \multirow{2}{*}{ p value } \\
\cline { 2 - 5 } Age & No. & $\mathbf{\%}$ & $\mathbf{N o .}$ & $\mathbf{\%}$ & & \\
3 & & & & & & \\
4 & 54 & 44.3 & 122 & 100 & & .00001 \\
5 & 59 & 57.8 & 102 & 100 & 32.618 & \\
6 & 121 & 72.0 & 168 & 100 & & \\
\hline Class & 100 & 74.1 & 135 & 100 & & \\
Balwadi & 45 & 66.2 & 68 & 100 & & \\
Pre kg & 16 & 32.0 & 50 & 100 & 49.466 & .00001 \\
LKG & 33 & 45.2 & 73 & 100 & & \\
UKG & 45 & 57.7 & 78 & 100 & & \\
Ist std & 195 & 75.6 & 258 & 100 & & \\
\hline Sex & & & & & & \\
Boys & 166 & 63.6 & 261 & 100 & .011 & \\
Girls & 168 & 63.2 & 266 & 100 & & \\
\hline Schools & & & & & & \\
Private & 137 & 49.6 & 276 & 100 & 47.134 & 0.0001 \\
Government & 197 & 78.5 & 251 & 100 & & \\
\hline
\end{tabular}

The prevalence of caries in 3 year old children was $44.3 \%$, 4 year old was $57.8 \%$, 5 year old was $72.0 \%$ and in 6 year old it was $74.1 \%$. It is seen from the table that as the age increases the prevalence of dental caries increases. Thus it is inferred that there is high statistical association between increasing age and prevalence of dental caries. $\left(\mathrm{X}^{2}=32.62, \mathrm{p}=.0001\right)$. The statistical significance difference between classes and dental caries prevalence also proves the same $\operatorname{fact}\left(\mathrm{X}^{2}=49.466, \mathrm{p}=.0001\right)$. There was no statistical difference between gender and prevalence of caries. The prevalence of caries between males and females were similar. Private school children had lesser caries prevalence compared to government school children. There was statistically significant difference between the two schools $\left(\mathrm{X}^{2}=47.134\right.$, $\mathrm{p}=$.0001).

Table 5. Severity of dental caries based on dmft index

\begin{tabular}{|l|l|l|l|}
\hline dmft & Caries severity & No. & \% \\
\hline 0 & No caries & 179 & 34.0 \\
1 & Very mild & 124 & 23.5 \\
$2-3$ & Mild & 152 & 28.8 \\
$4-5$ & Moderate & 54 & 10.2 \\
6 and above & Severe & 18 & 3.5 \\
\hline
\end{tabular}

This table shows that $34 \%$ of children had no caries, $23 \%$ had very mild caries, $28.5 \%$ had mild caries, $10.2 \%$ had moderate caries and only $3.5 \%$ of the children had severe caries.

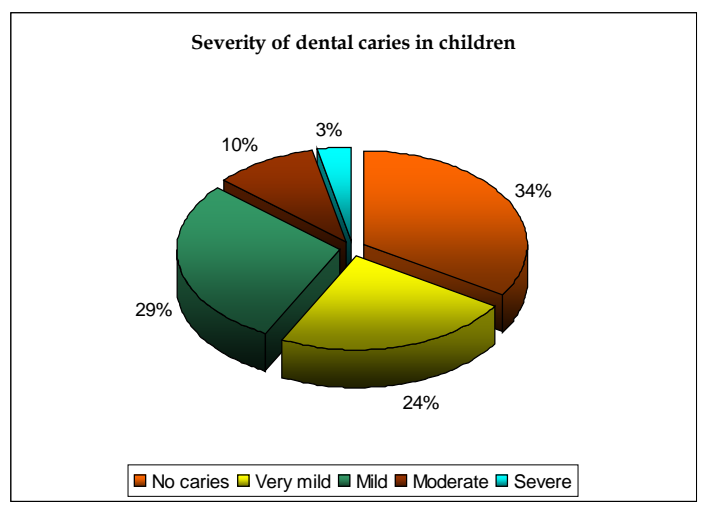

Table 6. Intra analysis of dmft index

\begin{tabular}{|l|c|c|c|c|c|c|c|c|}
\hline \multirow{2}{*}{ Factors } & \multicolumn{2}{|c|}{ Decayed teeth } & \multicolumn{2}{c|}{ Missing teeth } & \multicolumn{2}{c|}{ Filled teeth } & \multicolumn{2}{c|}{ dmft } \\
\cline { 2 - 8 } & Mean & SD & Mean & SD & Mean & SD & Mean & SD \\
\hline Schools & & & & & & & & \\
Private & .89 & 1.18 & .20 & .18 & .33 & .79 & 1.26 & 1.55 \\
Government & 1.63 & 1.37 & .26 & .51 & .11 & .32 & 1.98 & 1.77 \\
\hline Age & & & & & & & & \\
3 & .83 & 1.10 & .10 & .29 & .26 & .79 & 1.16 & 1.49 \\
4 & 1.17 & 1.47 & .12 & .35 & .25 & .64 & 1.54 & 1.85 \\
5 & 1.42 & 1.32 & .15 & .41 & .21 & .54 & 1.77 & 1.70 \\
6 & 1.47 & 1.31 & .20 & .47 & .16 & .55 & 1.83 & 1.69 \\
\hline Sex & & & & & & & & \\
Boys & 1.22 & 1.31 & .13 & .39 & .20 & .61 & 1.54 & 1.68 \\
Girls & 1.27 & 1.34 & .15 & .40 & .24 & .64 & 1.67 & 1.72 \\
\hline
\end{tabular}

It is observed from the table that private schools had less decayed and missing component and more filled component compared to the government schools. The decayed, missing and the dmft scores is seen to increase with age. Boys and girls had almost similar dmft scores.

Table 7. Intra analysis of $\mathrm{dmfs}$ index

\begin{tabular}{|c|c|c|c|c|c|c|c|c|}
\hline \multirow[b]{3}{*}{ Factors } & & & tra ana & & & & & \\
\hline & \multicolumn{2}{|c|}{ Decayed surfaces } & \multicolumn{2}{|c|}{ Missing surfaces } & \multicolumn{2}{|c|}{ Filled surfaces } & \multicolumn{2}{|c|}{ dmfs } \\
\hline & Mean & SD & Mean & SD & Mean & SD & Mean & SD \\
\hline \multicolumn{9}{|l|}{ Schools } \\
\hline Corporation \& Balwadi & 2.71 & 2.68 & .84 & 1.71 & .11 & .40 & 3.66 & 4.05 \\
\hline \multicolumn{9}{|l|}{ Age } \\
\hline 3 & 1.29 & 2.03 & .22 & .90 & .30 & .94 & 1.81 & 2.84 \\
\hline 4 & 1.73 & 2.66 & .37 & 1.14 & .29 & .78 & 2.39 & 3.56 \\
\hline 5 & 2.11 & 2.37 & .49 & 1.34 & .24 & .63 & 2.83 & 3.41 \\
\hline 6 & 2.27 & 2.26 & .70 & 1.62 & .16 & .54 & 3.11 & 3.55 \\
\hline \multicolumn{9}{|l|}{ Sex } \\
\hline Boys & 1.86 & 2.35 & .41 & 1.28 & .22 & .71 & 2.49 & 3.30 \\
\hline Girls & 1.91 & 2.35 & .50 & 1.33 & .27 & .74 & 2.68 & 3.45 \\
\hline
\end{tabular}


Government schools had more decayed and missing component $(2.71, .84)$ compared to the private school children. The decayed surfaces, missing surfaces and dmfs scores increased with increase in age. The dmfs scores between boys and girls were similar.

Testing significance between caries status and factors associated with it

Prevalence of dental caries and oral hygiene practices

The prevalence of dental caries in children using finger was $75.4 \%$ but the prevalence was only $61.8 \%$ in children using brush for cleaning their teeth. There was statistically significant difference between the mode of cleaning and the prevalence of caries. $\left(\mathrm{X}^{2}=4.303, \mathrm{p}=.038\right)$. In the study caries status was not related to other oral hygiene practices such as number of times of brushing, materials used in brushing, timings of changing the brush and the habit of rinsing the mouth.

\section{Eating habits in relation to presence or absence of} caries

The knowledge on whether sweets are bad for teeth and the timings in which they are taken seems to have no association with prevalence of caries as there is no significant difference between them. There was high statistically significant difference in number of sweets or chocolate taken with the presence or absence of dental caries in children $\left(\mathrm{X}^{2}\right.$ trend $\left.=50.39, \mathrm{p}=.001\right)$.

Table 8. Socio economic status in relation to dental caries

\begin{tabular}{|c|c|c|c|c|c|c|}
\hline Factors & \multicolumn{2}{|c|}{$\begin{array}{c}\text { DC } \\
\text { Prevalence }\end{array}$} & \multicolumn{2}{|c|}{ Total } & \multirow{2}{*}{$\begin{array}{c}\mathbf{X}^{\mathbf{2}} \\
\text { trend }\end{array}$} & $\begin{array}{c}\text { p } \\
\text { value }\end{array}$ \\
\hline Socio economic status & No. & $\%$ & No. & $\%$ & & \\
Missing information & 20 & 80.0 & 25 & 100 & & \multirow{2}{*}{41.257} \\
\hline Low & 173 & 77.6 & 223 & 100 & .0001 \\
\hline Middle & 114 & 53.3 & 214 & 100 & & \\
\hline High & 27 & 41.5 & 65 & 100 & & \\
\hline
\end{tabular}

The caries prevalence is $77.6 \%$ in low socio economic status children, $53.3 \%$ in middle socio economic and only $41.5 \%$ in high socio economic status children. It is inferred from the table that there is increase in prevalence of dental caries with decrease in socio economic status. $\left(\mathrm{X}^{2}\right.$ trend $\left.=45.126, \mathrm{p}=.0001\right)$.

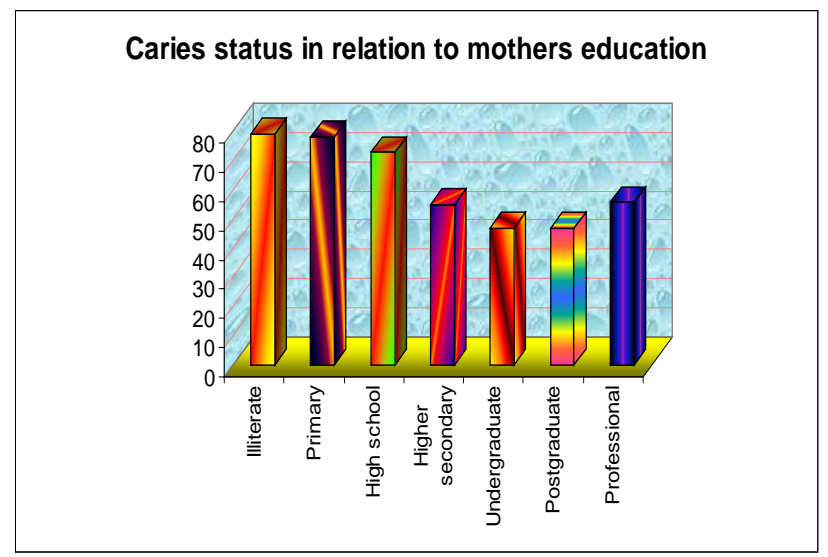

\section{Educational level of parents in relation to dental caries} status

In the association between literacy level and caries prevalence, it was inferred that children whose parents have higher literacy level have less caries prevalence. The prevalence of caries increases with decreasing level of literacy. There is high statistically significant association between dental caries, mother's educational level $\left(\mathrm{X}^{2}=\right.$ 48.81, $\mathrm{p}=.0001)$ and father's educational level $\left(\mathrm{X}^{2}=\right.$ 50.063, $\mathrm{p}=.0001)$.

Risk assessment between caries status and factors associated with dental caries

Table 9. Risk assessments between caries status and oral hygiene practices

\begin{tabular}{|c|c|c|c|c|c|c|c|c|c|}
\hline \multirow{4}{*}{ Factors } & & \multirow{2}{*}{\multicolumn{4}{|c|}{ Dental Caries }} & & & \multirow{2}{*}{\multicolumn{2}{|c|}{ dmfs }} \\
\hline & \multirow{3}{*}{ Total } & & & & & \multicolumn{2}{|l|}{ dmft } & & \\
\hline & & \multicolumn{2}{|c|}{ Present } & \multicolumn{2}{|c|}{ Absent } & \multirow{2}{*}{ Mean } & \multirow{2}{*}{ SD } & \multirow{2}{*}{ Mean } & \multirow{2}{*}{ SD } \\
\hline & & No & $\%$ & No & $\%$ & & & & \\
\hline \multicolumn{10}{|l|}{ Mode of cleaning } \\
\hline Finger & 61 & 46 & 75.4 & 15 & 24.6 & 2.08 & 1.96 & 3.64 & 3.95 \\
\hline Brush & 466 & 288 & 61.8 & 178 & 38.2 & 1.54 & 1.65 & 2.44 & 3.27 \\
\hline & & \multicolumn{4}{|c|}{$\begin{array}{l}\mathrm{OR}=1.89 \\
95 \% \text { CI } 1.03-3.49\end{array}$} & \multicolumn{2}{|c|}{$\begin{array}{l}\mathrm{t}=2.35 \\
\mathrm{p}=0.019\end{array}$} & \multicolumn{2}{|c|}{$\begin{array}{l}\mathrm{t}=2.61 \\
\mathrm{p}=0.009\end{array}$} \\
\hline
\end{tabular}

In an attempt made in comparing the association between mode of tooth brushing and caries status it was found that $75.4 \%$ of children using finger had dental caries and caries was present in only $61.8 \%$ of children using brush. It was inferred that children using finger for brushing is 1.89 times at a risk for developing dental caries compared to children using brush for cleaning their teeth $(\mathrm{OR}=1.8995 \% \mathrm{CI}=1.03-3.49)$. The mean $\mathrm{dmft}$ and dmfs index was also high for those who brushed using finger compared to those using brush. There was statistically high significant difference between the modes of cleaning the teeth and caries severity $(\mathrm{dmft} t=2.35, \mathrm{p}=$ 0.019, dmfs $\mathrm{t}=2.61 \mathrm{p}=0.009$ ).

Table 10. Risk assessments between caries status and no. of sweets taken

\begin{tabular}{|c|c|c|c|c|c|c|c|c|c|}
\hline \multirow{3}{*}{ Factors } & \multirow{3}{*}{ Total } & \multicolumn{4}{|c|}{ Dental Caries } & \multicolumn{2}{|l|}{ dmft } & \multicolumn{2}{|l|}{ dmfs } \\
\hline & & \multicolumn{2}{|c|}{ Present } & \multicolumn{2}{|c|}{ Absent } & \multirow{2}{*}{ Mean } & \multirow{2}{*}{ SD } & \multirow{2}{*}{ Mean } & \multirow{2}{*}{$\mathrm{SD}$} \\
\hline & & No & $\%$ & No & $\%$ & & & & \\
\hline \multicolumn{10}{|l|}{ No. of sweets taken } \\
\hline More than once & 186 & 156 & 83.9 & 30 & 16.1 & 2.60 & 1.87 & 4.38 & 3.98 \\
\hline \multirow[t]{2}{*}{ Nil or once } & 341 & 178 & 52.2 & 163 & 47.8 & 1.06 & 1.31 & 1.60 & 2.51 \\
\hline & & \multicolumn{4}{|c|}{$\begin{array}{l}\text { OR }=4.762 \\
95 \% \mathrm{CI}=3.052-7.429\end{array}$} & \multicolumn{2}{|c|}{$\begin{array}{l}\mathrm{t}=11.008 \\
\mathrm{p}=.0001\end{array}$} & \multicolumn{2}{|c|}{$\begin{array}{l}\mathrm{t}=9.782 \\
\mathrm{p}=.0001\end{array}$} \\
\hline
\end{tabular}


It is observed from the table that as the number of sweets eaten was more the prevalence of caries was also high. The odds of getting caries are 4.8 times higher in children eating more sweets than in children eating one or no sweets. $(\mathrm{OR}=4.762,95 \% \mathrm{CI}=3.052-7.429)$

Mother's educational level was compared with dental caries prevalence and was found that mothers of children with education less than high school had high caries prevalence of $77.8 \%$. Children whose mothers had more than high school education had comparatively lesser caries prevalence of $49.3 \%$. It was also found that the odds of developing dental caries was 3.6 times higher in children whose mothers were not well educated compared to children's of educated mother's.

Children of fathers who were not educated above high school had higher caries prevalence of $78.1 \%$ compared to children of fathers above higher secondary education who had only $50 \%$ prevalence of caries. It was also inferred that the children of fathers with less than high school education were 3.6 times at higher risk of getting dental caries compared to children of fathers with more than high school education.

\subsection{Multivariate Analysis Results}

Table 11. Factors affecting Dental caries through multivariate logistic regression analysis

\begin{tabular}{|l|c|c|c|c|c|}
\hline Factor & $\boldsymbol{\beta}$ & $\mathbf{S E}(\boldsymbol{\beta})$ & p value & OR & $\mathbf{9 5 \% ~ C I ~}$ \\
\hline $\begin{array}{l}\text { No. of sweets } \\
\text { taken }\end{array}$ & 1.626 & .243 & .001 & 5.085 & $3.15-8.19$ \\
\hline $\begin{array}{l}\text { Mothers } \\
\text { educational } \\
\text { level }\end{array}$ & 1.187 & .218 & 0.001 & 3.277 & $2.138-5.025$ \\
\hline Age & .319 & .096 & 0.001 & 1.376 & $1.140-1.661$ \\
\hline
\end{tabular}

Logistic regression was done for estimating the magnitude of association between dental caries and factors affecting dental caries. Variables age, number of sweets eaten per day, socio economic status of children, mother's educational level and father's educational level were included in the model in a stepwise method. Number sweets eaten per day mother's educational level and age were taken up in the final model and they showed statistical significance.

It was concluded that children eating more number of sweets per day are at 5 times more risk of developing caries. $(\mathrm{OR}=5.085,95 \% \mathrm{CI}=3.15-8.19)$. The odds of getting caries was 3 times more in children whose mothers were not educated above high school (OR $=3.277$, 95\% CI = 2.138-5.025). The study also showed that with increasing age the children were at 1.3 times more risk of developing caries $(\mathrm{OR}=1.376,95 \% \mathrm{CI}=1.140-1.661)$.

\section{Discussion}

Dental Caries essentially a product of affluence and civilization now forms an alarming health risk in children. This study has mainly focused on dental caries status of children between the age group of $3-6$ years and has highlighted the high burden of illness due to caries. The results of the study are in general agreement with the previous work of several authors.

The main objective of the study was to find the prevalence, severity and associated factors of dental caries. The prevalence of dental caries was found to be $63.4 \%$ in the study samples. This shows a high prevalence of caries in the 3-6 year old children, and it may be attributed to various risk factors. The prevalence of dental caries between gender was similar in this study and this result is supported by results of C.H.Chu et al [1]. Factors influencing severity were also very similar to those influencing prevalence.

Similar to the other previous studies $[2,3,4]$ the caries experience in the present study was found to be increasing significantly from 3 years to 6 years age group. The severity of caries also increased with increasing age, it was further inferred from the study that the 6 year old children were at 3.6 times higher risk of having caries. This increasing trend may be partly due to increased consumption of sugar containing food, change in dietary habits and non use of proper oral hygiene measures. Caries experience with age advancement might also be due to more exposure of teeth to the oral environment, as caries is a continuous and cumulative process [5].

The results of the study showed a significantly high association between oral hygiene practice of cleaning the teeth with finger and higher prevalence of dental caries. The children using finger were found to have more severe dental caries compared to children using brush. It was also inferred that children using finger were at 1.89 times higher risk of getting caries. This result was in accord with the results of Retnakumari. N, Songchai Thiasomakul $[3,6]$. This shows that finger may not completely clean the grooves, fissures and proximal areas of the teeth and the teeth may be more susceptible to caries. The frequency of tooth brushing, that is brushing once daily or twice daily revealed no significant association with the prevalence of dental caries in the study. The findings suggest that prolonged participation by parents in tooth cleaning is a necessary component in a preschool child's dental hygiene and that quality of cleaning rather than a mere cleaning twice daily must be stressed. As the tooth brushing by children under ten years of age is inefficient, difficulty can be explained by the lack of motivation and poor manual dexterity normal to this age [7].

In studying the eating habits of children, it was observed that there was an increasing trend with number of sweets eaten per day and the prevalence of dental caries. This is in agreement with the results of Lehl $G$ [8]. The mean dmft and dmfs scores were also found to be higher in children eating more sweets. The odds of having dental caries were 4.8 times higher in children eating more sweets.

The present study shows that economic status is one of the contributing factors for developing dental caries. Low prevalence of dental caries was found among high socio economic status and it showed an increasing trend in middle and low socio economic status children. This Socio economic status related trend was reported in studies in many countries $[9,10]$. The study also showed an increasing severity of caries with decreasing socio economic status. Children coming from low socio economic status were at 3.9 times at higher risk of getting caries compared to children in the middle and high socio economic status. Socioeconomic status has been considered as a determinant factor in caries risk assessment studies. Considered at an individual level socio economic status may influence dental caries in several ways. According to Evans et al, low family 
income may affect food selection and nutrient intake by mothers and also infants during the tooth development period. It may also affect the degree of education, health values, life-style and access to health care information. The differences in the decayed teeth, missing teeth and filled teeth between the Socio economic groups might be due to the benefit of preventive measures, early diagnosis and specific treatment which are affordable by the high economic group children than the middle and low economic group children. As a consequence, family income can be a proxy indicator for tooth susceptibility to caries.

Parent's literacy level and caries prevalence showed high statistical association in the study. Children whose mothers and fathers who were educated below high school were 3.6 times more risk of developing dental caries. The logistic regression results further confirmed that low literacy level in mothers was a significant risk factor for development of caries. The severities of dental caries were also high for the children whose parents were less educated compared to children with educated parents. This is supported by results of Retnakumari.N [3]. Parents with better attitude and more knowledge will probably build up better oral health habits in their children and look after the children's oral health.

Caries appears to be a disease of poverty, as much as of neglected health. It is also clear that caries can lead to some distressing health consequences, which the poor section of society can ill afford. The limitations of the study include that dental caries was measured using only visual and tactile response; this could have missed the diagnosis of early or proximal caries. In the study it was difficult to prove the fact that knowledge that sugar was bad for teeth and frequency of tooth brushing had an effect on caries status. The reason for this is that it was a cross sectional study and this can be proved only by a case control or cohort study. But it is unethical to perform a cohort study to prove temporal association as the children should be given intervention immediately and cannot be deprived of treatment for the sake of the study.

Preventive approaches seem to be a viable alternative to tackle the seemingly overwhelming problem of dental caries. The preventive approach can include two strategies viz; Population strategy and High risk strategy. A population strategy seeks to control common causes of caries incidence. It is done by providing preventive treatment for all subjects; this is thought to be useful in populations with high caries occurrence, because its goal is to change the distribution of the disease by controlling the determinants of caries in the whole population. According to the high-risk strategy, individuals with a high risk of caries are identified and preventive measures are taken to diminish their risk. The results of the study shows high prevalence of dental caries which could further lead to complication and crippling resulting in other health problems. Caries preventive efforts should be focused on young children as the benefits are cumulative.

\section{Conclusion}

Oral health promotion should particularly be targeted to areas of need to redress inequalities. Policy-makers should be aware of the role of fluoride in caries prevention and should press for fluoridation of water supplies where oral disease levels are highest. Non dental personnel such as primary care and education professionals may be used to pass on oral health knowledge and influence choices of defined target populations. Awareness and motivation should be built in parents also to have a wholesome preventive approach against dental caries.

\section{Acknowledgements}

Nil.

\section{Statement of Competing Interest}

Nil.

\section{References}

[1] C.H. Chu, D.S.H. Fung, E.C.M.LO; Dental caries status of preschool children in Hong Kong: British dental Journal 1999; 187: 616-620.

[2] Sogi G.M. Bhaskar D.J. ;Dental caries and Oral Hygiene Status of school children in Davangere related to their Socio - Economic levels : An Epidemiological study: J Indian Soc Pedo Prev Dent December (2002) 20 (4): 152-157.

[3] Retnakumari N; Prevalence of dental caries and risk assessment among primary school children of 6-12 years in the Varkala municipal area of Kerala: J Indian Soc Pedo Prev Dent 1999; 17:4:135-142.

[4] Tewari.S, Tewari. S., Rohtak; Caries experience in 3- 7 year old children in Haryana (India): J Indian Soc Pedod Prev Dent 2001; 19:2:52-56.

[5] Dash J.K., Sahoo P.K., Bhuyan S.K. Sahoo S.K. (2002); Prevalence of dental caries and treatment needs among children of Cuttack (Orissa): J Indian Soc Pedo Prev Dent December (2002) 20 (4) : 139-143.

[6] Songchai Thitasomakul, PhD, Odontology Dental Caries, Oral Hygiene and Dietary Habits A study of 2 to 6-year-old Buddhist and Muslim Thai children.

[7] Soraya Coelho, Ana Cristina Barreto, Orlando Ayrton; Effectiveness of Teaching Methods for Toothbrushing in Preschool Children:Braz Dent J (2002) 13(2): 133-136.

[8] Lehl G., Bansal K, Sekhon R; Relationship between cariogenic diet and dental caries as evaluated from a 5- day diet diary in 4-12 year old children: J Indian Soc Pedo Prev Dent 1999; 17: 4: 119121.

[9] M.H. Hobdell, E. R. Oliveira, R. Bautista, N.G. Myburgh, R. Lalloo, Narendran and N. W. Johnson (2003) Oral diseases and socio-economic status (SES) British dental journal volume 194 no. 2 January 252003.

[10] Denise M. P. Spolidorio1 José F. Höfling Daniella Moreira Janaina A. de O. Rodrigues Marcelo F. G. Boriollo Edvaldo A. R. Rosa (2003); Dental caries status in deciduous and permanent dentition of Brazilian children aged 6-8 years with a socioeconomic base: Braz J Oral Sci. January/March 2003, Vol. 2 - Number 4. 